\section{Influence of Pre-Curing Different Adhesives on the Color Stability of Cemented Thin Ceramic Veneers}

\author{
Orides Ferrari de Oliveira $\mathrm{Jr}^{1}{ }^{\mathbb{D}}$, Patrícia Valéria Manozzo Kunz ${ }^{1}{ }^{\circ}$, Flares \\ Baratto Filho ${ }^{1}{ }^{\circ}$, Gisele Maria Correr $^{1}{ }^{\circ}$, Leonardo Fernandes da Cunha ${ }^{1}$, \\ Carla Castiglia Gonzaga ${ }^{1}$ [C
}

'Graduate Program in Dentistry, UP - Universidade Positivo, Curitiba, PR Brazil

Correspondence: Carla Castiglia Gonzaga, Rua Prof. Pedro Viriato Parigot de Souza, 5300, 81280330 Curitiba, PR, Brasil. Tel: +55-41-3317-3180. e-mail: carlacgonzaga2@gmail.com

\begin{abstract}
The objective was to evaluate the color stability of thin ceramic veneers as a function of the curing mode (with and without pre-cure) of different adhesive systems applied to the internal surface of ceramics. Five adhesive systems (Scotchbond Multi-Purpose, Single Bond Universal, Gluma 2 Bond, Ambar, and Ambar APS) and photo-cured resin cement (Allcem Veneer) were used for cementing $0.6 \mathrm{~mm}$-thick feldspathic veneers (Mark II) on composite resin substrates (Charisma Diamond). The groups, according to adhesive system, were divided into two subgroups $(n=10)$ : i) adhesive and resin cement were polymerized separately (pre-cure of the adhesive), ii) adhesive and resin cement were polymerized simultaneously. The CIELab color parameters were determined with a spectrophotometer at $24 \mathrm{~h}$ (baseline), 7 days, 30 days and 12 months. Data were analyzed by two-way ANOVA and Tukey's test $(\alpha=0.05)$. The results indicated statistically significant differences for adhesive systems and time. The mode of curing of the adhesive system was not statistically significant: pre-cured adhesives $(2.6 \pm 1.3)$ and not pre-cured adhesives $(2.8 \pm 1.4)$. For the adhesives, $\Delta \mathrm{E}$ values varied in the following order: Ambar-APS $(1.6 \pm 0.5)<$ Scotchbond Multi-Purpose $(2.6 \pm 1.2)$ = Gluma 2 Bond $(2.7 \pm 1.2)=$ Ambar $(2.9 \pm 1.2)<$ Single Bond Universal $(3.5 \pm 1.5)$. For time, $\Delta \mathrm{E}$ values were: 7 days $(1.7 \pm 0.7), 30$ days $(3.5 \pm 1.2)$ and 12 months $(2.9 \pm 1.3)$. It can be concluded that the different adhesive systems used for cementing thin ceramic veneers influenced the final color of the indirect restorations. The adhesives curing mode did not present a significant effect in the color stability of thin ceramic veneers.
\end{abstract}

Key Words: dental adhesives, color stability, photo-activation, aging, ceramic laminates.

\section{Introduction}

All-ceramic restorations with a high degree of translucency allow the passage of light (1); therefore, the color characteristics of the dental substrate on which they are cemented as well as the materials used for cementation greatly influence the overall color (2). Several studies report that color changes in the resin cement used for cementation may become visible, affecting the final aesthetic appearance of the restoration, which in turn leads to treatment failure (2-4). However, for cementing ceramic laminates to the dental substrate with conventional resin cements, two layers of adhesive system are used: one between the ceramic and the cement, and another between the cement and the dental structure. Yet, little is known about the influence of the adhesive system and its pre-cure on the color stability of thin ceramic laminates.

It has been reported that different adhesive systems used in composite resin direct restorations influenced the final color of the restoration (5). It is not yet known whether the adhesive layer used on the internal surface of indirect ceramic restorations causes a similar effect; especially in thin ceramic laminate veneers, which may also interfere with the color stability and final aesthetic result of these restorations in the short and long term.

The cementation of ceramic laminates can be achieved using photo-activated resin cements, or either flowable or pre-heated composite resins, which require the application of an adhesive system for bonding to the dental substrate. In general, these adhesives are applied as a surface treatment on the inner surface of ceramic restorations, after conditioning with hydrofluoric acid and silanization. Simplified conventional adhesives have, in general, a relatively high amount of solvent in their composition. Consequently, nano-infiltration from the environment into the hybrid layer of these adhesives may possibly occur (6). In contrast, an adhesive system containing a hydrophobic layer, such as the three-step etch-and-rinse and two-step self-etching adhesives, tend to present lower hydrolytic degradation and increased longevity at adhesion interfaces when compared to simplified adhesives (7). Universal adhesives have proven to be more stable in regard to hydrolytic degradation due to changes in their chemical composition (8). It must be highlighted that the greater the hydrophilic characteristics and solvent content 
in an adhesive system or composite are, the higher the degradation rate and, possibly, color change are expected to be (9).

Among adhesive system components, the photoinitiator may play a particularly important role regarding the coloring and color stability of adhesive systems and composites. Camphorquinone is the main photoinitiator (a photosensitive molecule that absorbs light and leads to the formation of reactive species) used in most resin-based materials. However, despite promoting the polymerization of monomers and assuring good mechanical properties, camphorquinone has the significant disadvantages of having an intense yellow color and the need for a co-initiator component, which oxidizes over time (10). Depending on the quantity and concentration of camphorquinone in the material, it may develop an undesirable yellowish color, even influencing the color stability in the long term (11). This yellowish color in adhesive systems, for example, may affect the final aesthetic result in the cementation of thin ceramic laminates. For this reason, in order to minimize aesthetic problems due to discoloration, camphorquinone has been partially or completely replaced by other photosensitive molecules in some adhesive systems and composites.

More recently, virtually colorless adhesive systems have been introduced with the purpose of causing less interference with the final aesthetic result of thin ceramic restorations. Since each adhesive system may present a coloration resulting from its monomeric composition and type and amount of photoinitiator, it becomes important to know how adhesive use in the internal treatment of thin ceramic restorations can influence the final color stability of the restoration, after definitive cementation.

Regarding the photo-activation time, there is still no consensus in the literature as to whether the adhesive system layer in the ceramic laminate inner surface must be pre-cured or photo-activated simultaneously to the resin cement $(12,13)$. On one hand, pre-curing the adhesives can increase the degree of conversion, but can interfere with the fit of the veneer, depending on the thickness of the applied adhesive layer. On the other hand, simultaneous photo-activation with the resin cement may reduce the clinical time and does not interfere with the adaptation of the restoration. However, there is no information regarding the influence of the photo-activation time of the adhesive on the color stability of thin ceramic laminates. Thus, the objective of this study was to evaluate the 12 month-color stability of thin ceramic laminate veneers as a function of the curing mode (with and without pre-cure) of different adhesive systems applied to the internal surface of the ceramics. The null hypotheses were: i) the application of different adhesive systems on the inner surface of the ceramics would not influence the final color after cementation; ii) pre-curing of the adhesive layer applied to the internal surface of the ceramic would not influence the final color of thin laminate veneers after cementation.

\section{Material and Methods}

One hundred and twenty disks of composite resin (Charisma Diamond, Kulzer, Hanau, Germany, shade B1) were made with $5 \mathrm{~mm}$ diameter and $1 \mathrm{~mm}$ thick, using a polytetrafluoroethylene matrix, interposed between two glass slides and two polyester strips (TDV, Pomerode, SC, Brazil). The composite resin was placed in a single increment and light activated with a LED photo-curing unit (Radii-cal, SDI, Bayswater, Australia) with $1200 \mathrm{~mW} / \mathrm{cm}^{2}$ irradiance for $20 \mathrm{~s}$. The irradiance of the photo-curing unit was checked before use and the battery was charged completely. These composite resin disks served as the substrate for the cementation of the ceramic laminate veneers.

Blocks of feldspathic ceramics (shade 2M1, VITABLOCS Mark II, Vita Zahnfabrik, Bad Säckingen, Germany) were cut into $0.6 \mathrm{~mm}$-thick veneers using a low speed diamond saw (IsoMet 1000, Buehler, Lake Bluff, IL, USA) under refrigeration.

For cementation on the composite resin substrate, the inner surface of each ceramic laminate was conditioned with 5\% hydrofluoric acid (Condac Porcelana, FGM, Joinville, SC, Brazil) for $60 \mathrm{~s}$, washed in running water for $20 \mathrm{~s}$, and dried. A layer of silane coupling agent (Prosil, FGM, Joinville, SC, Brazil) was applied for 60 s, followed by a layer of the tested adhesives. For standardization purposes, the excess of adhesive was removed with a microbrush in all samples. The tested adhesives were: Scotchbond MultiPurpose (hydrophobic adhesive, 3M ESPE, St. Paul, MN, USA), Single Bond Universal (3M ESPE), Gluma 2 Bond (Kulzer, Hanau, Germany), Ambar (FGM), and Ambar APS (FGM) (Fig. 1). The composition of the materials is presented in Table 1.

The composite resin disks were conditioned with 37\% phosphoric acid (Condac 37, FGM) for $20 \mathrm{~s}$, washed in running water for $20 \mathrm{~s}$, and dried. Next, the same adhesive used on the inner face of the ceramic was applied, removing the excess with a microbrush. The adhesive layer was photo-activated for $10 \mathrm{~s}$. The ceramic laminates were then cemented on the composite resin disks, using a photo-cured resin cement (shade E-Bleach, AllCem Veneer ; FGM) and each specimen was photo-activated for $40 \mathrm{~s}$. The luting was performed under digital pressure until the ceramic veneers was completely bonded to the resin base, in order to simulate clinical conditions. After the cement photoactivation, the final thickness of the specimen was measured using a digital caliper, and all sets (resin base, cement, and ceramic veneer) measured between 1.8 and $2 \mathrm{~mm}$.

The photo-activation of the adhesive layer on the inner surface of the ceramic laminates was carried 
out under two conditions ( $n=10)$ : i) adhesive and resin cement were polymerized separately (pre-cure of the adhesive), ii) adhesive and resin cement were polymerized simultaneously. In this second group, the adhesive layer was applied on the surface of the ceramic laminate and was not cured before the cementation. The cement was applied on the ceramic and the components placed into position, and the adhesive + cement layer was polymerized at the same time. Ten minutes after cementation, the specimens were stored in distilled water at $37^{\circ} \mathrm{C}$, changed weekly during the whole evaluation period.

Color stability after the cementation was evaluated with a spectrophotometer (EasyShade Advance, Vita Zahnfabrik, Bad Sackingen, Germany). For each reading, the specimens were removed from the water, dried with absorbent paper, and placed on a flat surface with a white standard background, in order to prevent any background interference. In addition, the spectrophotometer was always positioned in the center of the specimen, at a $90^{\circ}$ angle to the surface, and it was calibrated before the readings. The initial color record was made $24 \mathrm{~h}$ after cementation (baseline), and after 7 days, 30 days, and 12 months.

Color stability was evaluated by measuring the color difference $(\Delta \mathrm{E})$ between color measurement readings after storage for various times and at baseline, utilizing the $L^{*}, a^{*}$, and $b^{*}$ coordinates of ClELab system, where $L^{*}$ indicates luminosity, $a^{*}$ stands for the amount of red or green $\left(+a^{*}=r e d,-a^{*}=\right.$ green $)$ and $b^{*}$ corresponds to the amount of yellow or blue $\left(+b^{*}=\right.$ yellow, $-b^{*}=$ blue). $\Delta E$ was calculated in accordance with the formula:

$$
\Delta \mathrm{E}=\left[\left(\Delta \mathrm{L}^{*}\right)^{2}+\left(\Delta \mathrm{a}^{*}\right)^{2}+\left(\Delta \mathrm{b}^{*}\right)^{2}\right]^{1 / 2}
$$

where $\Delta \mathrm{L}^{*}$ indicates the luminosity difference between the final reading for the different times and the baseline, and $\Delta \mathrm{a}^{*}$ and $\Delta \mathrm{b}^{*}$ represent the difference between the parameters $a^{*}$ and $b^{*}$ for the baseline and the final reading at different times.

Data were statistically analyzed by two-way ANOVA (adhesive system and curing mode) with repeated measures and Tukey's HSD test, with a significance level of 0.05 .

\section{Results}

Means and standard deviations for $\Delta \mathrm{E}$ values are presented in Table 2.

The results showed significant statistical differences for adhesive system $(p<0.001)$ and storage time $(p<0.001)$. The curing mode was not statistically significant $(p=0.348)$. All double interactions $(p<0.001)$ and the triple interaction $(p=0.006)$ were statistically significant.

For the adhesive system, the mean $\Delta \mathrm{E}$ values varied as follows: Ambar-APS $(1.6 \pm 0.5)^{\mathrm{a}}<$ Scotchbond MultiPurpose $(2.6 \pm 1.2)^{\mathrm{b}}=$ Gluma 2 Bond $(2.7 \pm 1.2)^{\mathrm{b}}=$ Ambar $(2.9 \pm 1.2)^{\mathrm{b}}<$ Single Bond Universal $(3.5 \pm 1.5)^{\mathrm{c}}$. The results for adhesive curing mode did not show statistically significant differences: adhesive pre-curing $(2.6 \pm 1.3)^{\mathrm{a}}$ and simultaneous curing $(2.8 \pm 1.4)^{\text {a }}$. As for storage time, mean $\Delta$ E values were: $(1.7 \pm 0.7)^{\text {a }}$ for 7 days, $(3.5 \pm 1.2)^{c}$ for 30 days and $(2.9 \pm 1.3)^{b}$ for 12 months.

\section{Discussion}

The color of an indirect restoration depends on

Table 1. Composition of materials for the cementation of the ceramic laminates

\begin{tabular}{|c|c|c|}
\hline Material & Classification & Composition \\
\hline $\begin{array}{l}\text { Scotchbond Multi- } \\
\text { Purpose (3M ESPE, St. } \\
\text { Paul, MN, USA) }\end{array}$ & $\begin{array}{l}\text { Etch-and-rinse, three- } \\
\text { step adhesive system }\end{array}$ & Hydrophobic adhesive: Bis-GMA, HEMA, tertiary amines, and photoinitiators \\
\hline $\begin{array}{l}\text { Single Bond Universal (3M } \\
\text { ESPE, St. Paul, MN, USA) }\end{array}$ & Universal adhesive system & $\begin{array}{l}\text { Bis-GMA, HEMA, dimethacrylates, ethanol, camphorquinone, } \\
\text { functional copolymer of polyalkenoic acids, ethylmethylketone, } \\
\text { initiators, silica filler, MDP, and silane }\end{array}$ \\
\hline $\begin{array}{l}\text { Gluma } 2 \text { Bond (Heraeus } \\
\text { Kulzer, Hanau, Germany) }\end{array}$ & $\begin{array}{l}\text { Etch-and-rinse, two- } \\
\text { step adhesive system }\end{array}$ & Methacrylate, photoinitiator, excipients, and glutaraldehyde \\
\hline $\begin{array}{l}\text { Ambar (FGM, Joinville, } \\
\text { SC, Brazil) }\end{array}$ & $\begin{array}{l}\text { Condition-and- } \\
\text { wash adhesive } \\
\text { systems, two steps }\end{array}$ & $\begin{array}{l}\text { Methacrylic monomers, photoinitiators, co-initiators, } \\
\text { stabilizer, inert filler (silica nanoparticles), and ethanol }\end{array}$ \\
\hline $\begin{array}{l}\text { Ambar APS (FGM, } \\
\text { Joinville, SC, Brazil) }\end{array}$ & $\begin{array}{l}\text { Etch-and-rinse, two- } \\
\text { step adhesive system }\end{array}$ & $\begin{array}{l}\text { MDP, methacrylic monomers, photoinitiating composition } \\
\text { (APS, Advanced Polymerization System), co-initiators, } \\
\text { stabilizer, silica nanoparticles, and ethanol }\end{array}$ \\
\hline $\begin{array}{l}\text { Charisma Diamond (Heraeus } \\
\text { Kulzer, Hanau, Germany) }\end{array}$ & Composite resin & $\begin{array}{l}\text { UDMA-based organic matrix (containing } 64 \mathrm{vol} \% \text { filler, } 5 \mathrm{~nm}-20 \mu \mathrm{m} \text { ), } \\
\text { barium and aluminum fluoride glass and highly dispersed nano particles }\end{array}$ \\
\hline $\begin{array}{l}\text { Allcem Veneer (FGM, } \\
\text { Joinville, SC, Brazil) }\end{array}$ & Light-cured resin cement & $\begin{array}{l}\text { Methacrylic monomers, camphorquinone, co- initiators, stabilizers, pigments, } \\
\text { glass particles of silanized barium-aluminum-silicate, and silicon dioxide }\end{array}$ \\
\hline
\end{tabular}

Bis-GMA: bisphenol A glycidyl methacrylate; HEMA: 2-hydroxyethyl methacrylate; UDMA: urethane dimethacrylate; MDP: 10-methacryloyloxydecyl dihydrogen phosphate 
several factors; among them, the optical properties of the restorative materials and materials selected for cementation, the thickness of these materials, and the color or type of substrate. The color stability of resin cements or the type and thickness of ceramics has been evaluated (14-15). However, an adhesive system is applied between the luting agent and the ceramics, and between the cement and the dental substrate, with the purpose of improving the wettability and bonding of the substrates. It has been demonstrated that the adhesives are an important factor for the color stability of direct composite resin

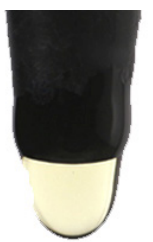

Scotchbond Multi-Purpose (Adhesive)

Figure 1. Visual appearance of the different adhesives evaluated in the present study. It is possible to note in the image the color difference among the tested adhesives.

Table 2. Means and standard deviations for $\Delta \mathrm{E}$ values.

\begin{tabular}{lcccc}
\hline \multirow{2}{*}{$\begin{array}{l}\text { Adhesive } \\
\text { system }\end{array}$} & Curing mode & \multicolumn{3}{c}{ Time } \\
\cline { 3 - 5 } & & $\Delta \mathrm{E} 7 \mathrm{days}$ & $\Delta \mathrm{E} 30 \mathrm{days}$ & $\Delta \mathrm{E} 1 \mathrm{year}$ \\
\hline \multirow{2}{*}{$\begin{array}{l}\text { Scotchbond } \\
\text { Multi-Purpose }\end{array}$} & Pre-cure & $1.6 \pm 0.5 \mathrm{Aab}$ & $4.0 \pm 0.4 \mathrm{Bbc}$ & $3.3 \pm 0.9 \mathrm{Bbc}$ \\
& Simultaneous & $1.5 \pm 0.2 \mathrm{Aab}$ & $3.4 \pm 0.4 \mathrm{Bbc}$ & $1.6 \pm 0.9 \mathrm{Abc}$ \\
Single Bond & Pre-cure & $1.6 \pm 0.4 \mathrm{Aab}$ & $4.0 \pm 0.8 \mathrm{Bc}$ & $4.2 \pm 1.2 \mathrm{Bc}$ \\
Universal & Simultaneous & $2.8 \pm 0.9 \mathrm{Ac}$ & $4.8 \pm 1.0 \mathrm{Bc}$ & $3.6 \pm 1.8 \mathrm{Abc}$ \\
& Pre-cure & $1.1 \pm 0.4 \mathrm{Aa}$ & $3.2 \pm 0.6 \mathrm{Bbc}$ & $3.0 \pm 0.9 \mathrm{Bbc}$ \\
Gluma 2 Bond & Simultaneous & $2.0 \pm 0.2 \mathrm{Aab}$ & $4.2 \pm 0.4 \mathrm{Bc}$ & $2.6 \pm 0.8 \mathrm{Aab}$ \\
& Pre-cure & $1.0 \pm 0.1 \mathrm{Aa}$ & $3.1 \pm 0.4 \mathrm{Bb}$ & $3.1 \pm 0.7 \mathrm{Bbc}$ \\
Ambar & Simultaneous & $2.3 \pm 0.4 \mathrm{Ab}$ & $4.4 \pm 0.7 \mathrm{Cc}$ & $3.4 \pm 1.0 \mathrm{Bbc}$ \\
& Pre-cure & $1.4 \pm 0.4 \mathrm{Aa}$ & $1.6 \pm 0.4 \mathrm{Aa}$ & $1.9 \pm 0.4 \mathrm{Aa}$ \\
Ambar APS & Simultaneous & $1.1 \pm 0.3 \mathrm{Aa}$ & $1.7 \pm 0.6 \mathrm{Aa}$ & $1.8 \pm 0.2 \mathrm{Aa}$ \\
\hline
\end{tabular}

In each row, values followed by the same capital letters are statistically similar ( $p>0.05)$. In each column, values followed by the same lowercase letters are statistically similar $(\mathrm{p}>0.05)$. restorations (5). A similar result was found by this study, as the tested adhesives influenced the color stability of thin ceramic laminates. Therefore, the first hypothesis, that the application of different adhesive systems on the internal surface of the ceramic would not influence the color of the thin ceramic laminates after cementation, was rejected.

The results of this study showed that the specimens where Ambar APS was used at the interface between ceramic and resin cement presented the lowest color change when compared to the other adhesive systems tested. One of the possible reasons for this may be the composition of this adhesive, which is free of Bis-GMA that would result in the absence of monomers containing aromatic rings that are frequently associated with processes of pigmented byproduct formation. Also, the higher color stability of this adhesive may be the result of its differentiated photoinitiator system, using smaller quantities of camphorquinone. Therefore, this adhesive system, visually, is practically colorless, and avoids interference with the aesthetic result of the restorations, mainly thin ceramic laminate veneers in anterior teeth.

The result obtained by Scotchbond Multi-Purpose adhesive may be due to its hydrophobic characteristics in relation to other tested simplified adhesives, which have greater amounts of solvents, making them more hydrophilic and more likely to present greater degradation and color change (9). In a previous study, a hypothesis was proposed to explain color and translucency alteration after water storage in specimens containing a simplified adhesive system (16). Initially, the solvent molecules of the simplified adhesive were retained in the structure of the composite resin during polymerization. After the period of water immersion, the solvent had already been eliminated from a large part of the material, forming free spaces that, afterwards, could be filled up with water. This process would facilitate light propagation, increasing the translucency and influencing color changes. Regarding the Single Bond Universal, its unfavorable result with greater color change can be explained by the higher acidity. The literature reports that high acidity has been associated with hydrophilicity and water sorption, thus impairing color stability (17). For example, the $\mathrm{pH}$ values for conventional adhesives are between 3.4 and 5.9 (Scotchbond 
Multi-Purpose and Single Bond 2); for the self-etching and universal adhesives (Clearfil SE Bond and Single Bond Universal), the $\mathrm{pH}$ tends to be lower, ranging from 1.4 to $2.6(18,19)$.

The final color change of the cemented ceramic laminates was determined after aging for 7 days, 30 days, and 12 months in distilled water at $37^{\circ} \mathrm{C}$. The configuration of the specimens used in this research simulates a clinical situation in which the adhesive interfaces are protected from contact with water by the subjacent resin, representing the dental substrate, and by the ceramic restoration. However, the adhesive interfaces at the margins of the restoration can be exposed to oral fluids and, consequently, to hydrolytic degradation and staining. Storage in water is frequently used as a means of in vitro aging. It is known that water sorption can lead to the degradation of the adhesive through the plasticization of the polymer network and reduction of the shear forces between the polymer chains (20). Water sorption occurs due to the small size of the water molecule, which can diffuse into the spaces between the polymer chains of the adhesive network (21). In addition, the evaluated adhesives have methacrylate monomers, like Bis-GMA and HEMA, with polar functional groups, such as carboxyl, phosphate, and hydroxyl groups. The hydrogen bond between the water molecules and the polar groups in the polymer matrix disrupts the hydrogen bonds between the chains and may result in structural damage, changes in refraction index, and color alteration (22).

Studies report that $\Delta \mathrm{E}$ values above 3.3 are considered to be clinically unacceptable (23). The results showed that, for all evaluated adhesives and conditions, the color change was clinically acceptable after 7 days. However, after 30 days of water storage, $60 \%$ of the groups had $\Delta E$ values above 3.3. If the 12-month aging condition is considered, only the Ambar APS group, with and without pre-curing, presented $\Delta \mathrm{E}$ values below 3.3 in all situations and had no statistically significant difference between the results for different storage times. In the present study, the $\Delta \mathrm{E}$ values could be considered relatively low, even after one year of storage in distilled water. With these low $\Delta E$ values, the differences in the deltas of the individual coordinates $\left(\Delta \mathrm{L}^{*}, \Delta \mathrm{a}^{*}\right.$ and $\left.\Delta \mathrm{b}^{*}\right)$ tend to be equivalent or even smaller than $\Delta \mathrm{E}$. In an attempt to how a different perspective on the results, the deltas of individual coordinates were calculated. After one year, $\Delta \mathrm{L}^{*}$ ranged from 0.28 to 2.68 , $\Delta \mathrm{a}^{*}$ ranged from -0.65 to 0.45 and $\Delta \mathrm{b}^{*}$ ranged from 0.60 to 3.13 , indicating that the specimens tended to become a little darker, more red and more yellow.

The second hypothesis, that pre-curing of the adhesive layer applied to the internal surface of the ceramic would not influence the final color of thin laminate veneers after cementation, was accepted, since the curing mode of the adhesive system did not show statistically significant differences.

The internal surface of the ceramic restoration must be treated in accordance with its microstructure and composition. For feldspathic ceramics and glass-ceramics, an application of 5\% hydrofluoric acid, for $60 \mathrm{~s}$ and $20 \mathrm{~s}$, respectively, is recommended, followed by the application of a layer of silane coupling agent, for $60 \mathrm{~s}$. The protocol is clear up until this step, practically without significant variations in the literature. However, from this point on, the sequence can vary depending on the type of restoration (veneers or onlays, and crowns) and on the manufacturers of the ceramics, adhesive systems, and resin cements. For thicker restorations, like onlays and crowns, it is generally recommended that a layer of the adhesive system be applied after the silane, and that this adhesive layer be pre-cured, before inserting the resin cement. In contrast, for ceramic veneers and laminates, the protocols can vary or are not so specific and mostly recommend the application of an adhesive system layer without pre-curing, if specified by the adhesive manufacturer (24). Some manufacturers, in their technical profiles, indicate this procedure, recommending that the adhesive system not be pre-cured, but photoactivated simultaneously to the resin cement. However, a significant number of instructions of use for adhesive systems or even the recommendations of ceramic producers neither offer specific directions for the treatment of the internal surface of the ceramic (for both thicker restorations and laminate veneers), nor clearly specify whether the adhesive should be pre-cured or not.

Of the two layers of adhesive used for cementing ceramic laminate veneers to the dental substrate with conventional resin cements - one layer of adhesive applied between the resin cement and the ceramic laminate and another applied between the dental structure and the resinous cement - more importance has been given to the one applied between the cement and the dental structure. For this layer, recommendations regarding pre-cure of the adhesive are also controversial. One can infer that the pre-cure of this layer would assure a better-polymerized hybrid layer with improved mechanical properties and higher bond strength.

The influence of polymerized and non-polymerized adhesive systems on the layer thickness and dentin bond strength after inlay cementation was investigated in a previous study. Scanning electron microscopy revealed that without adhesive photopolymerization, no adhesive layer could be distinguished from the resin cement. The isolated photopolymerization of the adhesive produced a thicker film, the thickness depending on the region along the inner edge of the indirect restoration; however, the adhesive photo-activation had no significant effect on the 
bond strength for most of the tested adhesive systems (25). The effects of adhesive system application techniques (with or without pre-cure) on the microleakage and marginal adaptation of composite resin indirect veneers showed that the highest and lowest microleakage values appeared at the dentin margins of the groups cemented with etchand-rinse adhesive system with and without adhesive layer pre-cure, respectively. No adhesive layer was seen for the adhesives using simultaneous photo-activation with the cement. The adhesives pre-cured showed better resistance to dye penetration, although the film thickness of these materials was slightly increased (26).

Finally, it should be pointed out that the main reason for not pre-curing adhesive layers before insertion of the indirect restorations is that pooling of the adhesive could interfere with the complete seating of the restoration (26).

Composite resin was used to standardize the substrate as much as possible for all specimens, eliminating the influence of factors that could not be controlled when using natural teeth, such as differences in opacity and shade among the teeth, differences in enamel and dentin thickness, and differences in the hybrid layer formed on each substrate. Using composite resin as substrate, the variations could be minimized because shade, thickness and the degradation of the substrate were similar in all groups. It is also important to note that visual color alteration was not observed in any of the evaluated groups. Qualitative analyzes, using visual shade guides, were not used in the present study, because they contain limited shades when compared with instrumental color analysis. Additionally, visual shade matching is affected by factors such as viewer interpretation, environmental influences and illumination conditions. Thus, quantitative analyzes performed with spectrophotometers are recommended to evaluate the color differences more accurately.

The adhesive cementation of ceramic restorations is a complex procedure, which requires knowledge of adhesion principles and strict observance to the clinical protocol in order to assure bonding between the dental structure and the restorative material. The application of a properly chosen adhesive system, with the correct technique, will allow successful clinical results more predictability in the long term. It can be concluded that adhesive systems used in the cementation of thin ceramic laminate veneers influenced the final color of the restorations. The precuring of the adhesive layer did not present a significant effect on the color stability of the thin ceramic laminates.

\section{Resumo}

0 objetivo deste estudo foi avaliar a estabilidade de cor de laminados cerâmicos de espessura fina em função do momento de ativação de diferentes sistemas adesivos na superficie interna das cerâmicas. Foram utilizados 5 sistemas adesivos (Scotchbond Multiuso, Single Bond Universal, Gluma 2 Bond, Ambar and Ambar APS) e o cimento resinoso fotoativado (Allcem Veneer) para cimentação de lâminas de cerâmica feldspática (Mark II) com 0,6 mm de espessura, sobre substratos de resina composta (Charisma Diamond). Os grupos, de acordo com o sistema adesivo utilizado, foram divididos em dois subgrupos $(n=10)$ : i) adesivo e cimento resinoso foram polimerizados separadamente (polimerização isolada do adesivo), ii) adesivo e cimento resinoso foram polimerizados ao mesmo tempo (polimerização simultânea). Os parâmetros de cor do sistema CIELab foram determinados com um espectrofotômetro nos tempos de $24 \mathrm{~h}$ (baseline), 7 dias, 30 dias e 12 meses. Os dados foram analisados por ANOVA a dois fatores e teste de Tukey $(\alpha=0,05)$. Os resultados indicaram diferenças estatísticas significantes para os sistemas adesivos e tempo. 0 momento da fotoativação do sistema adesivo não foi estatisticamente significante: polimerização prévia $(2,6 \pm 1,3)$ e polimerização simultânea $(2,8 \pm 1,4)$. Para o sistema adesivo, os valores médios de $\Delta \mathrm{E}$ variaram na seguinte ordem: Ambar APS $(1,6 \pm 0,5)<$ Scotchbond Multi-Purpose $(2,6 \pm 1,2)=$ Gluma 2 Bond $(2,7 \pm 1,2)=$ Ambar $(2,9 \pm 1,2)<$ Single Bond Universal $(3,5 \pm 1,5)$. Para o fator tempo o $\Delta \mathrm{E}$ foi: 7 dias $(1,7 \pm 0,7), 30$ dias $(3,5 \pm 1,2)$ e 12 meses $(2,9 \pm 1,3)$. Pode-se concluir que os diferentes sistemas adesivos utilizados na cimentação de laminados cerâmicos de espessura fina influenciaram na cor final das restaurações. 0 momento da fotoativação, isolada ou simultânea ao cimento resinoso, não apresentou efeito significativo na estabilidade de cor dos laminados cerâmicos de espessura fina.

\section{Acknowledgements}

This research project from Centro de Pesquisa da Universidade Positivo was funded with public resources obtained through the "Public Call 09/2016 - Institutional Program for Basic and Applied Research" - Fundação Araucária /Secretaria de Estado da Ciência, Tecnologia e Ensino Superior do Paraná (SETI) - under protocol number 47954.

\section{References}

1. Chen C, Kleverlaan CJ, Feilzer AJ. Effect of an experimental zirconiasilica coating technique on micro tensile bond strength of zirconia in different priming conditions. Dent Mater 2012;28:127-134.

2. Turgut $S$, Bagis B. Color stability of laminate veneers: $A n$ in vitro study. J Dent 2011;39:57-64.

3. Archegas LR, Freire A, Vieira S, Caldas DB, Souza EM. Colour stability and opacity of resin cements and flowable composites for ceramic veneer luting after accelerated ageing. J Dent 2011;39:804-810.

4. Marchionatti AM, Wandscher VF, May MM, Bottino MA, May LG. Color stability of ceramic laminate veneers cemented with lightpolymerizing and dual-polymerizing luting agent: A split-mouth randomized clinical trial. J Prosthet Dent 2017;118:604-610

5. Gaintantzopoulou M, Kakaboura A, Loukidis M, Vougiouklakis G. A study on colour stability of self-etching and etch-and-rinse adhesives. J Dent 2009;37:390-396.

6. Chiaraputt $S$, Roongrujimek $P$, Sattabanasuk V, Panich $N$, Harnirattisai C, Senawongse P. Biodegradation of all-in-one self-etch adhesive systems at the resin-dentin interface. Dent Mater J 2011;30:814-826.

7. Feitosa VP, Leme AA, Sauro S, Correr-Sobrinho L, Watson TF, Sinhoreti $M A$, Correr $A B$. Hydrolytic degradation of the resin-dentine interface induced by the simulated pulpal pressure, direct and indirect water ageing. J Dent 2012;40:1134-1143.

8. Pashaev D, Demirci M, Tekçe N, Tuncer S, Baydemir C. The effect of double-coating and times on the immediate and 6-month dentin bonding of universal adhesives. Biomed Mater Eng 2017;28:169-185.

9. Sedrez-Porto JA, Münchow EA, Cenci MS, Pereira-Cenci T. Translucency and color stability of resin composite and dental adhesives as modeling liquids - A one-year evaluation. Braz Oral Res 2017;31:54.

10. Albuquerque PP, Moreira AD, Moraes RR, Cavalcante LM, Schneider LF. Color stability, conversion, water sorption and solubility of dental composites formulated with different photoinitiator systems. J Dent 2013;41:67-72.

11. Ilie N, Hickel R. Can CQ be completely replaced by alternative initiators in dental adhesives? Dent Mater J 2008;27:221-228. 
12. Gresnigt M, Ozcan M. Esthetic rehabilitation of anterior teeth with porcelain laminates and sectional veneers. J Can Dent Assoc 2011;77:143.

13. da Cunha LF, Prochnow RA, Costacurta AO, Gonzaga CC, Correr GM. Replacement of anterior composite resin restorations using conservative ceramics for occlusal and periodontal rehabilitation: an 18-month clinical follow-up. Case Rep Dent 2016;2016:9728593.

14. Silami FDJ, Tonani R, Alandia-Román CC, Pires-de-Souza FCP. Influence of different types of resin luting agents on color stability of ceramic laminate veneers subjected to accelerated artificial aging. Braz Dent J 2016;27:95-100.

15. Rodrigues RB, Lima E, Roscoe MG, Soares CJ, Cesar PF, Novais VR. Influence of resin cements on color stability of different ceramic systems. Braz Dent J 2017;28:191-195.

16. Münchow EA, Sedrez-Porto JA, Piva E, Pereira-Cenci T, Cenci MS. Use of dental adhesives as modeler liquid of resin composites. Dent Mater 2016;32:570-577.

17. Tay FR, Pashley DH. Have dentin adhesives become too hydrophilic? J Can Dent Assoc 2003;69:726-731.

18. Dong CC, McComb D, Anderson JD, Tam LE. Effect of mode of polymerization of bonding agent on shear bond strength of autocured resin composite luting cements. J Can Dent Assoc 2003;69:229-234.

19. Isolan CP, Valente LL, Münchow EA, Basso GR, Pimentel AH, Schwantz $\mathrm{JK}_{\text {, et }}$ al. Bond strength of a universal bonding agent and other contemporary dental adhesives applied on enamel, dentin, composite, and porcelain. Appl Adhes Sci 2014;2:25.

20. Ferracane JL, Berge HX, Condon JR. In vitro aging of dental composites in water--effect of degree of conversion, filler volume, and filler/ matrix coupling. J Biomed Mater Res 1998;42:465-472.

21. Soles $\mathrm{CL}$, Yee AF. A discussion of the molecular mechanisms of moisture transport in epoxy resins. JPoly Sci B Poly Phys 2000;38:792-802.

22. Ping ZH, Nguyen QT, Chen SM, Zhou JQ, Ding YD. States of the water in different hydrophilic polymers-DSC and FIR studies. Polymer 2001;42:8461-8467.

23. Ruyter IE, Nilner K, Moller B. Color stability of dental composite resin materials for crown and bridge veneers. Dent Mater 1987;3:246-251.

24. Santos Jr GC, Santos MJ, Rizkalla AS. Adhesive cementation of etchable ceramic esthetic restorations. J Can Dent Assoc 2009;75:379-384.

25. Santos MJ, Bezerra RB. Fracture resistance of maxillary premolars restored with direct and indirect adhesive techniques. J Can Dent Assoc 2005;71:585.

26. Maleknejad F, Moosavi H, Shahriari R, Sarabi N, Shayankhah T. The effect of different adhesive types and curing methods on microleakage and the marginal adaptation of composite veneers. J Contemp Dent Pract 2009;10:18-26
Received October 29, 2018 Accepted December 5, 2018 